\title{
Price-elasticity based customer segmentation in the Italian auto insurance market
}

Received (in revised form): 29th May, 2004

\section{Guglielmo Barone}

is undertaking a doctorate in statistics at the University of Bologna. His interests encompass the econometrics of consumption behaviour and empirical industrial organisation. He has been working at Prometeia SrL as senior consultant since 2000.

\section{Mariano Bella}

is a partner of Prometeia SrL and head economist of its consumption area. He has published in Economics Letters, Economic Notes and Micro \& Macro Marketing. He is the author of a number of papers covering different economic subjects, from marketing to international trade theory and applied econometrics.

Mariano Bella Prometeia SrL, Via Marconi, 43, 40122 Bologna, Italy.

Tel: +39051 6480911 ; Fax: +39051220 753; e-mail: mariano.bella@prometeia.it

Abstract As an anticipated response to the foreseeable increase in competition, insurance companies in Italy are trying to escape the commodity trap by supplying a wide range of services to their customers. Sociodemographic segmentations have been shown to fail in identifying target groups towards which to concentrate qualified marketing efforts, including pricing policies. This paper proposes a segmentation based on customer-estimated price elasticities which are the operational variables for willingness-to-pay. The authors think that it is the only effective segmentation to give some useful insights in differentiating prices and services, in order to maximise revenues or profits. With respect to the Italian compulsory automotive insurance market, it is proved that customer demand curves and related price elasticities are quite heterogeneous. The tool proposed, exploiting a large amount of the existing willingness-to-pay, seems to offer a good and effective basis for valuable price discrimination at the firm level, also dropping the size of the potential switching rate implicit in a non-efficient price differentiation method.

\section{INTRODUCTION}

In the 1990s, Italy's compulsory auto insurance market was liberalised to permit companies to price their insurance contracts as they saw fit. A truly competitive market, however, is still far off because of a number of factors, including the lack of rules governing claims against a company's assets and liabilities. Furthermore, and perhaps more simply, introducing competition requires time to change management's behaviour after half a century of total regulation.

In any case, in a couple of years what is true for major European countries will also become true for Italy: competition is increasing and insurance companies should start to price competitively. This prescription seems quite different from the commonly adopted Italian pricing strategy that could be referred as 'the good-bad-customer strategy'. According to this policy, insurers try to lose - or 
at least to avoid - bad customers (who ask or are expected to ask for high claim recoveries) and to acquire - or at least to retain - good customers (who behave or are expected to behave without any sort of accident). This strategy does not work, because, in the authors' opinion, there are neither good nor bad customers but only customers charged prices roughly matching their willingness-to-pay or, on the other hand, customers which firms are not able to charge efficiently.

To some extent it is impossible to tackle the problem concerning the most expensive part of the firm portfolio (in the actuarial sense of expected claims) and the issue is strictly connected to the mutual flattening approach of the insurance market. The solution could be to reduce the flat tariff approach by increasing the number of segments and, most importantly, defining each segment on behavioural grounds and not only on the basis of customers' sociodemographics. This is the approach proposed in this paper.

The value of each insurance contract could be thought of as the product of a price term by a quantity of one: the 'price' term reflects risk aversion (risk averse customers are willing to pay more to insure the same quantity of risk) while the 'quantity' term is linked to the different insured risk, depending for example on the kilometres travelled per year. The more heterogeneous the distribution of risk aversion, or the more heterogeneous the demand curves among consumers, the more heterogeneous should be the (measured) willingness-to-pay in the market or in the single firm's portfolios. As far as customers are concerned, this tenet does not necessarily mean higher prices. In fact it could be the case that price discrimination allows prices to match a customer's specific willingness-to-pay: prices will go up or down according to the consumer's demand schedule.

Heterogeneity in a consumer's willingness-to-pay can be captured by estimating price elasticities. The authors have undertaken such an exercise based on 1,000 consumer clusters belonging to one of the largest insurance companies in Italy, ensuring that the clusters are representative for both sociodemographics and behaviour of the Italian compulsory auto insurance market. The levels of competition between companies was not taken into account because in practice they actually act as monopolists within separated markets, as the very low average switching rate shows (below $7.5 \%$ in 2001-2002). ${ }^{1}$

As pointed out in Keaveney, ${ }^{2}$ prices are also at the core of competitive behaviour in determining brand loyalty, which is in turn the main driver of a firm's profitability. More explicitly, Bolton and Myers $^{3}$ state that price sensitivity is a key market-segmentation criterion and, accordingly, the authors of this paper think that particular attention should be devoted to price-based market segmentation, although psychological and behavioural antecedents might serve to explain the elasticity distribution among customers.

In this paper the focus is on a segmentation based on customer-estimated price elasticities. These parameters epitomise both objective (sociodemographics) and subjective (behavioural) characteristics of each (cluster of) customers. It is the only effective segmentation to give some useful insights in differentiating prices in order to maximise revenues or profits. After finding heterogeneous customer demand curves and related price elasticities, the proposal is to vary prices of insurance contracts in the firm's portfolio according to the inverse elasticity rule. By simulating revenue 
changes with respect to optimal and non-optimal pricing, it is shown that the described tool, exploiting a large amount of the existing willingness-to-pay, seems to offer a good and effective basis for valuable price discrimination at the firm level, also leading to a fall in the size of the potential switching rate implicit in a non-efficient price differentiation.

The paper is organised as follows: (i) short description of the Italian insurance market, (ii) discussion of the model on which the empirical evidence on price elasticities is based; (iii) data description and econometric results; (iv) simulation of different price policies in order to assess the effectiveness-of elasticity based price discrimination. Finally, the paper concludes with some comments on the strategy of increasing company revenues by efficient price changes, pointing out that pricing competitively is the first and necessary step to implement a wide range of marketing strategies mainly devoted to reducing the switching rate of customers.

\section{THE ITALIAN AUTO INSURANCE MARKET AT A GLANCE}

The automotive market is very important in Italy both in quantity and in value terms for the upgrading process that is pushing up the quality and value of the existing stock of circulating vehicles, with obvious consequences for the risk coverage demand faced by insurance companies (Table 1). In 2002 the stock of circulating vehicles - excluding motorbikes, trucks and lorries accounted for 29 million cars, corresponding to about 1.5 cars per household. The average value of a new car approached 15,000 euros, thanks to an increasing trend in demand for larger and safer vehicles. Moreover the demand for road mobility has been increasing up to now. ${ }^{4,5}$ These two factors underline an increasing demand for auto damage insurance. The third, and maybe the most important market characteristic, is the subjective perception of customers with respect to their need for auto damage insurance. This hidden component presently plays (and will definitely play in the next few years) a prominent role in the success of insurance companies, because nothing but the awareness of their own demand is likely to make customers buy more insurance services.

Despite the liberalisation that occurred in 1994, the market structure is far from being competitive, as shown by the increased concentration and the significant increase in the average premium paid by consumers.

This empirical evidence suggests that companies operate in quite separate markets, as also suggested by the very low switching rate $(7.5$ per cent) estimated for the Italian case. ${ }^{6}$ This implies conditions for all sorts of price discrimination. Companies, however, should be aware that this kind of rent will be reduced as soon as the competition becomes more effective. When separate markets tend to merge, the best way to retain customers with price discrimination is to price according to their willingness to pay. In fact, without switching costs, as it should be in a competitive market, the company will retain only those consumers charged less than their willingness to pay, which in turn depends on risk aversion and quantity of insured risk.

\section{METHODOLOGY}

It is well known that consumer 'type' is strongly related to willingness-to-pay. ${ }^{7}$ So it is proposed to proxy 'types' with demand elasticities as the basis for the pricing discrimination. Demand elasticities are estimated by modelling the customer response to the firm pricing 
Table 1: Car insurance market in Italy: Some relevant variables

\begin{tabular}{|c|c|c|c|c|c|c|c|c|c|}
\hline & 1994 & 1995 & 1996 & 1997 & 1998 & 1999 & 2000 & 2001 & 2002 \\
\hline Stock $(1,000$ s of cars $)$ & $27,148.1$ & $27,384.5$ & $27,634.2$ & $27,966.6$ & $28,356.1$ & $28,638.0$ & $28,799.6$ & $28,979.5$ & $29,095.9$ \\
\hline Circulating vehicles per person ${ }^{*}$ & 0.674 & 0.678 & 0.683 & 0.690 & 0.700 & 0.709 & 0.714 & 0.720 & 0.723 \\
\hline $\begin{array}{l}\text { Quality index }=(\% \text { cars }>1.6 \text { It }) / \\
\quad(\% \text { cars }<1.6 \mathrm{It})\end{array}$ & 0.36 & 0.38 & 0.42 & 0.45 & 0.49 & 0.53 & 0.58 & 0.62 & 0.67 \\
\hline $\begin{array}{l}\text { Compulsory auto insurance price } \\
\text { index }(1994=100)\end{array}$ & 100.0 & 107.5 & 112.8 & 122.9 & 135.3 & 152.4 & 163.5 & 176.4 & - \\
\hline$C 5^{\star *}$ & - & 53.0 & 53.5 & 52.2 & 51.2 & 57.4 & 57.3 & 58.5 & - \\
\hline $\begin{array}{l}\text { Compulsory car accident insurance } \\
\text { turnover (billions of euros) }\end{array}$ & - & 9.3 & 9.8 & 10.7 & 11.7 & 13.2 & 14.2 & 15.3 & 16.6 \\
\hline
\end{tabular}

*population aged between 18-70.

${ }^{* *}$ concentration index (sum of the market shares of the five largest firms) 
policy. Consumer behaviour is seen as a discrete choice: facing a certain premium, the consumer chooses whether to stay with the company or to switch to another one. After modelling the probability of switching, it is possible to evaluate price elasticities. The methodology is summarised in the following steps.

1) Segmentation: the customers' portfolio is segmented according to relevant social, behavioural and demographic variables (eg age, geographic area, ownership of life insurance, track record of accidents and so on). Segments are indexed by $\mathrm{i}=1$, $\ldots, I$ and $N_{i}$ is the number of insurance policies for each segment.

2) Each consumer in each segment, once observing her own premium pi chooses whether to stay with the firm with probability $\delta_{i} i=\delta_{i}\left(p_{i}\right)\left(0 \leq \delta_{i} \leq 1\right)$. The switching probability $\delta_{i}$ is modelled as a logit function of the premium $p_{i}$ :

$$
\delta_{i}\left(p_{i}\right)=\frac{\exp \left(\alpha_{i}+\beta_{i} p_{i}\right)}{1+\exp \left(\alpha_{i}+\beta_{i} p_{i}\right)} i=1, \ldots, \mathrm{I} .
$$

where $\alpha_{i}$ and $\beta_{i}$ are parameters to be estimated.

3) Definition of the target function: the target function of the firm is given by the total (expected) revenue. The company chooses $p=\left(p_{1}, \ldots p_{I}\right)$ in order to maximise $\sum_{i=1}^{I} p_{i} N_{i}\left(1-\delta_{i}\left(p_{i}\right)\right)$, ie the (expected) value of total revenues taking into account the reaction of its customers. The objective function was set according to the prevailing strategies of Italian insurance firms, aimed to maximise market share.

4) Optimal pricing policy: this takes into account the opposite effect of an increase in the premium; on one hand it obviously improves revenues but, on the other hand, it increases the switching probability, thus penalising expected revenues. The optimal trade-off is found in terms of rate-of-change with respect to a given prices vector because it is much easier from the firm's point of view to work on percentage price changes than directly on the prices themselves. After some manipulation the target function can be rewritten as

$$
\max _{r_{i}, \ldots, r_{I}} \sum_{i=1}^{I} p_{i, 0}\left(1+r_{i}\right) N_{i}\left(1-\delta_{i}\left(p_{i, 0}\right)\right.
$$

where $p_{0}=\left(p_{1,0}, \ldots, p_{I, 0}\right)$ is the vector of observed prices, $r=\left(r_{1}, \ldots, r_{I}\right)$ is the vector of price percentage variation, $N_{i}$ is the total number of policies per segment and

$$
\boldsymbol{\eta}_{i}\left(p_{i}\right)=\frac{d\left(1-\delta_{i}\left(p_{i}\right)\right) / d p_{i}}{1-\delta_{i}\left(p_{i}\right)} p_{i}<0
$$

is the elasticity of the demand of contracts to prices. In order to evaluate the potential benefit from price discrimination the target function (1) is maximised without constraint and subject to the following constraint:

$$
\begin{aligned}
& \frac{\sum_{i=1}^{I} p_{i, 0}\left(1+r_{i}\right) N_{i, 0}\left(1-\delta_{i}\left(p_{i, 0}\right)\right) / \sum_{i=1}^{I} N_{i, 0}\left(1-\delta_{i}\left(p_{i, 0}\right)\right)}{\sum_{i=1}^{I} p_{i, 0} N_{i, 0}\left(1-\delta_{i}\left(p_{i, 0}\right)\right) / \sum_{i=1}^{I} N_{i, 0}\left(1-\delta_{i}\left(p_{i, 0}\right)\right)} \\
& -1=\theta
\end{aligned}
$$

where the left-hand side expression is the rate of change of a weighted average premium. The value of constraint could come from various sources such as management or shareholder strategies or threats emerging from the competitive arena.

In this setting first order conditions of the unconstrained problem are

$$
r_{i}^{u}=-\frac{1+\eta_{i}\left(p_{i, 0}\right)}{2 \eta_{i}\left(p_{i, 0}\right)} i=1, \ldots, \mathrm{I} .
$$


Optimal solutions for the constrained problem must satisfy the following equations:

$$
r_{i}^{c}=\frac{\lambda}{2 \eta_{i}\left(p_{i, 0}\right)}-\frac{1+\eta_{i}\left(p_{i, 0}\right)}{2 \eta_{i}\left(p_{i, 0}\right)} \quad i=1, \ldots, \mathrm{I}
$$

together with the constraint (2), where $\lambda$ is the Lagrange multiplier associated to the constraint maximisation problem. If $\theta$ is less than the price index variation implied by unconstrained maximisation (a condition in which the constraint makes sense) then $\lambda>0$; so a rapid inspection of equation (4) reveals that in this case $(\lambda>0) r_{i}^{c}<r_{i}^{u} i=1, \ldots, \mathrm{I}$; moreover the rules (3-4) indicate that the more the absolute value of the elasticity the less is the change of price insurance contract requested by the optimal policy.

With the behavioural model in hand, attention can now be devoted to showing how it may work in a real competitive environment. In this way all the relevant information contained in a firm database - customer demographics, time series of premiums and insurance services for each customer, track records of claims, switching or staying behaviour in reaction to the firm price change - is exploited in order to offer a new tool aimed at pricing competitively.

\section{EMPIRICAL RESULTS}

This research is based on the car damage insurance portfolio of one of the most important insurance companies active in the Italian market. The portfolio considered accounts for about 1.5 million contracts per year and consumer automotive contracts and wide 'types' of buyers for a period of four years (1997-2000).

The data set consists of grouped individual information on clusters defined by cross-tabulating the social, demographic and behavioural variables listed in Table 2 with the main descriptive statistics of the most important variables in the data set (switching rates and premiums). All descriptive statistics and the econometrics computations have been run with SAS/STAT software.

For year $t$, the measured switching rate is the ratio between the number of cancelled policies during year $t$ and the total number of policies at the beginning of year $t$.

The statistics reported in Table 2 show a wide geographical coverage of the portfolio with both a representative cross-selling rate and an appealing age distribution of customers. Thus, the portfolio should not be biased by over-representation of particular types of customer with negative implications in terms of insurance behaviour.

As to average premiums, it should be noted how they are related to car power and to the age and sex of the driver, thus confirming the prominent role that objective characteristics play in price differentiation. Average prices summarised in the table are the starting point for the policy described in the last section in term of optimal rates of change.

Given that $A_{i t}$ is the number of cancelled policies in the $i$-th segment in year $t$ and $N_{i t}$ is the number of total policies in the $i$-th segment at the beginning of year $t$, the switching rate $\delta_{i t}=A_{i t} / N_{i t}$ as a logit function of average premium $S P_{i t}$ and its variation rate were modelled, to take into account the consumer reaction which is linked not only to the price level but also to its historical dynamics. The effects of exogenous variables on switching rate have been differentiated among segments using appropriate dummy variables both in the constant term and in the slope parameters. In the reduction process going from general (one set of parameters for 
Table 2: Main descriptive statistics of the data set

\begin{tabular}{|c|c|c|c|c|c|}
\hline & \multirow{2}{*}{$\begin{array}{l}\begin{array}{l}\text { Relative } \\
\text { frequency \% }\end{array} \\
2000\end{array}$} & \multicolumn{2}{|c|}{$\begin{array}{l}\text { Contract price in } \\
\text { year } 2000 \text { (euro) }\end{array}$} & \multicolumn{2}{|c|}{$\begin{array}{l}\text { Switching rate in } \\
2000 \%\end{array}$} \\
\hline & & Average & $\begin{array}{l}\text { Standard } \\
\text { error }\end{array}$ & Average & $\begin{array}{l}\text { Standard } \\
\text { error }\end{array}$ \\
\hline \multicolumn{6}{|l|}{ Geographic area: } \\
\hline North west & 18.2 & 420.8 & $3,330.7$ & 12.6 & 141.2 \\
\hline North east & 22.9 & 406.0 & $3,556.0$ & 12.6 & 156.0 \\
\hline Centre & 31.6 & 424.0 & $4,074.4$ & 13.6 & 181.4 \\
\hline South (including Sicily and Sardinia) & 27.3 & 349.5 & $3,471.3$ & 12.6 & 162.0 \\
\hline \multicolumn{6}{|l|}{ Sex } \\
\hline Male & 66.1 & 414.1 & $4,408.8$ & 13.4 & 191.2 \\
\hline Female & 33.9 & 369.6 & $2,792.5$ & 12.1 & 116.8 \\
\hline \multicolumn{6}{|l|}{ Age } \\
\hline $18-29$ & 10.3 & 513.8 & $2,321.9$ & 18.2 & 121.3 \\
\hline $30-59$ & 66.4 & 405.5 & $4,519.4$ & 13.0 & 186.2 \\
\hline$>60$ & 23.3 & 334.1 & $2,430.3$ & 10.5 & 98.7 \\
\hline \multicolumn{6}{|l|}{ Car power } \\
\hline$<=12 \mathrm{hp}$ & 26.4 & 280.4 & $1,438.1$ & 12.5 & 115.0 \\
\hline$>12 \mathrm{hp}$ & 73.6 & 441.6 & $3,362.1$ & 13.1 & 194.0 \\
\hline \multicolumn{6}{|l|}{ Contract } \\
\hline $\begin{array}{l}\text { Bonus/malus (premium } \\
\text { discount increase) }\end{array}$ & 27.9 & 364.1 & $2,603.8$ & 12.6 & 135.6 \\
\hline 4R (charge per accident incurred) & 72.1 & 412.4 & $4,478.8$ & 13.0 & 181.3 \\
\hline \multicolumn{6}{|l|}{ Fidelity (years) } \\
\hline$<=1$ & 18.1 & 437.7 & $3,230.5$ & 11.4 & 103.3 \\
\hline $2-6$ & 28.2 & 416.4 & $3,494.3$ & 17.1 & 146.5 \\
\hline$>=7$ & 53.7 & 377.3 & $4,216.4$ & 11.3 & 130.3 \\
\hline \multicolumn{6}{|l|}{ Other policies owned } \\
\hline No & 86.0 & 393.5 & $4,663.3$ & 13.4 & 197.9 \\
\hline Yes & 14.0 & 430.7 & $2,104.9$ & 10.2 & 70.0 \\
\hline \multicolumn{6}{|l|}{ Damages in $t-1$} \\
\hline No & 94.5 & 395.8 & $4,861.7$ & 12.5 & 178.5 \\
\hline Yes & 5.5 & 456.8 & $1,450.4$ & 20.9 & 91.6 \\
\hline Total portfolio & & 398.9 & $3,814.6$ & 12.9 & 161.7 \\
\hline
\end{tabular}

each segment) to particular (only the 37 parameters show in Table 3), many regressions were performed choosing which parameters were significantly different from zero or from each other, thus eliminating or aggregating both intercepts and slopes according to the statistical significance of the linear constraints.

The reduction process to specify a parsimonious model leads to the output of the final regression shown in Table 3.

The fitted model shows good statistical performance: parameters are statistically significant with the expected signs and the mean absolute percentage error (MAPE) on the switching rate $\delta_{i t}$ is about 13 per cent. The model shows that the track record of pricing which the customer faces does matter, as can be seen from the value and the statistical significance of both price terms (contemporaneous and lagged). Other things being equal, in terms of the price faced today by a customer belonging to a certain segment, the probability that the customer signs the contract decreases with the difference between that price and the price the customer paid the previous year. This relevant empirical evidence seems to 
Table 3: Regression output

\begin{tabular}{|c|c|c|}
\hline $\begin{array}{l}\text { Number of parameters } \\
\text { Number of observations } \\
\text { SSE } \\
\text { Root MSE } \\
\text { Adjusted R-squared }\end{array}$ & & $\begin{array}{r}37 \\
2,967 \\
153,995 \\
7.250 \\
0.9885\end{array}$ \\
\hline & Estimate & $t$ ratio \\
\hline Intercept (general parameter)* & -9.930 & -38.15 \\
\hline Female $^{*}$ & 0.348 & 14.51 \\
\hline Age $30-59^{*}$ & 1.527 & 25.99 \\
\hline Age $>=60^{\star}$ & 2.245 & 26.21 \\
\hline Car power $>12 \mathrm{hp}^{\star}$ & -2.402 & -22.44 \\
\hline 4R contract* & 0.155 & 16.32 \\
\hline Fidelity $2-6^{*}$ & 1.333 & 23.61 \\
\hline Fidelity $>=7^{*}$ & 1.942 & 25.73 \\
\hline Other policies ownership* & -0.336 & -15.06 \\
\hline Female and car power $>12 \mathrm{hp}^{\star}$ & 0.776 & 28.25 \\
\hline Car power $>12 \mathrm{hp}$ and damage in $t-1^{*}$ & -0.181 & -8.79 \\
\hline Age $30-59$ and fidelity $2-6^{*}$ & -0.087 & -3.85 \\
\hline Age $30-59$ and fidelity $>=7^{\star}$ & -0.305 & -13.38 \\
\hline Age $>=60$ and fidelity $2-6^{*}$ & -0.139 & -5.78 \\
\hline Age $>=60$ and fidelity $>=7^{\star}$ & -0.346 & -14.22 \\
\hline Damage in $t-1$ and other policies ownership* & -0.122 & -7.44 \\
\hline 4R contract and other policies ownership* & 0.058 & 4.53 \\
\hline Centre, car power $>12 \mathrm{hp}$ and fidelity $>=7^{*}$ & 0.088 & 6.25 \\
\hline South, car power $>12 \mathrm{hp}$ and fidelity $>=7^{\star *}$ & -0.044 & -2.49 \\
\hline Price (general parameter)* & $9.832 \mathrm{E}-6$ & 31.32 \\
\hline North east, age $>=60$ and damage in $t-1^{*}$ & $-367.907 \mathrm{E}-9$ & -10.2 \\
\hline Age $30-59$, fidelity $>=7$ and damage in $t-1^{\star}$ & $-285.428 \mathrm{E}-9$ & -12.36 \\
\hline Other policies ownership ${ }^{\star}$ & $-179.763 \mathrm{E}-9$ & -6.07 \\
\hline Fidelity $2-6^{*}$ & $-352.455 \mathrm{E}-9$ & -6.82 \\
\hline Fidelity $>=7^{*}$ & $-553.373 \mathrm{E}-9$ & -8.4 \\
\hline Damage in $t-1^{\star *}$ & $-122.338 \mathrm{E}-9$ & -2.45 \\
\hline Female* $^{\star}$ & $-548.555 \mathrm{E}-9$ & -14.66 \\
\hline North east and female* & $-107.512 \mathrm{E}-9$ & -5.27 \\
\hline Car power $>12 \mathrm{hp}^{*}$ & $-579.158 \mathrm{E}-9$ & -8.45 \\
\hline Age $>=60$ and car power $>12 \mathrm{hp}^{*}$ & $-196.857 \mathrm{E}-9$ & -9.64 \\
\hline $4 \mathrm{R}$ contract and damage in $t-1^{\star}$ & $-94.932 \mathrm{E}-9$ & -5.66 \\
\hline Price variation (general parameter) ${ }^{\star}$ & 1.105 & 18.86 \\
\hline Year $=1998^{*}$ & -0.247 & -48.92 \\
\hline Year $=2000$ and damage in $t-1^{*}$ & -0.162 & -14.09 \\
\hline North west ${ }^{\star}$ & -1.119 & -35.7 \\
\hline North east ${ }^{*}$ & -0.718 & -40.37 \\
\hline Centre $^{*}$ & -1.050 & -33.24 \\
\hline
\end{tabular}

* statistically significant at $1 \%$ level.

${ }^{* *}$ statistically significant at $5 \%$ level.

confirm the intuition that brand loyalty and retention - and possibly less price sensitivity - depend on past firm behaviour too.

The next step is to use the estimated parameters to compute price elasticities for different 'types' (segments). These form the basis for the inference the insurance company should make about customer behaviour and, consequently, for optimal pricing strategies. Elasticities, the average of which is about -1.1 , show a great variance (standard error $=0.6$ ), ranging from -0.1 to -20.0 . This implies that price discrimination is very important in terms of revenue maximisation.

The figures in Table 4 are the average elasticities by segmentation variable. Geographic area and type of contract do not seem to have a great impact on consumers' behaviour. Males are more reactive than females and younger people 
Table 4: Average elasticities by segmentation variables

\begin{tabular}{ll}
\hline Segmentation variables & $\begin{array}{l}\text { Price } \\
\text { elasticity }\end{array}$ \\
\hline North west & -1.1 \\
North east & -1.1 \\
Centre & -1.2 \\
South & -1.1 \\
Male & -1.2 \\
Female & -0.9 \\
Age 18-29 & -2.1 \\
Age 30-59 & -1.1 \\
Age $>=60$ & -0.7 \\
Car power < $=12 \mathrm{hp}$ & -0.8 \\
Car power $>12 \mathrm{hp}$ & -1.3 \\
Bonus/malus contract & -1.1 \\
4R contract & -1.1 \\
Fidelity <=1 & -1.2 \\
Fidelity 2-6 & -1.5 \\
Fidelity $>=7$ & -0.9 \\
No damage in $t-1$ & -1.1 \\
Damage in $t-1$ & -1.9 \\
No other policies ownership & -1.2 \\
Other policies ownership & -0.9 \\
\hline
\end{tabular}

are more sensitive than older. The interpretation of this last piece of evidence may be reinforced in that switching costs have become lower for young people because of their use of the web and other technologies which reduce information/transaction costs. The ownership of other policies (as a proxy of successful cross-selling activities) reduces, on average, the elasticity to price: it is a signal that, from the customers' viewpoint, it is important to have a unique company from which to buy all risk coverage products/services.

Another way to appreciate the segmentation process is shown in Figure 1 where the frequency distribution of elasticities of the 989 segments is plotted, together with the indication of their relative weight on the firm portfolio. The right-hand area, corresponding to 43.2 per cent of portfolio, is characterised by elasticities greater than 1.1 in absolute value. It is the area in which the firm should reduce prices. In the central area (22.1 per cent of portfolio) the insurance company faces elasticities near to 1 and thus the present pricing should not be changed. The left-hand area signals clusters of segments whose elasticity is lower than 0.9. With regard to this part of the portfolio (about 34.7 per cent), the firm should raise prices, obtaining switching less than proportional to the price increase.

Given this analysis the tools for pricing according to estimated willingness-to-pay are finally available.

\section{FROM ELASTICITIES TO PRICING}

It is straightforward to compute optimal prices variation rate using equations (3) and/or (4). In order to evaluate the relevance of price discrimination, a counterfactual experiment was run, comparing total expected revenues in two opposite scenarios: no discrimination and perfect discrimination (among segments), the rate of change of a price index of a policy being equal in both situations. In other words, pricing strategies that brought the same rate of change to the average premium were compared. In the simulations the switching process is applied to the whole customer base observed at the beginning of year 2000. The two simulated strategies are then compared to the observations at the end of the same year.

As the simulations show, the insurance company can increase its total revenues by 6.1 per cent with respect to the non-discriminated pricing and by 4.8 per cent above the actual revenue, only by adopting a thoughtful pricing strategy. Optimal pricing implies a price index variation rate equal to 5.2 per cent. If the company has another target, one has to run the constrained problem.

Table 6 parallels Table 5 with a different (suboptimal) price index variation rate. The problem was solved with a constraint on the price index (it has been raised by 2.0 per cent in the 


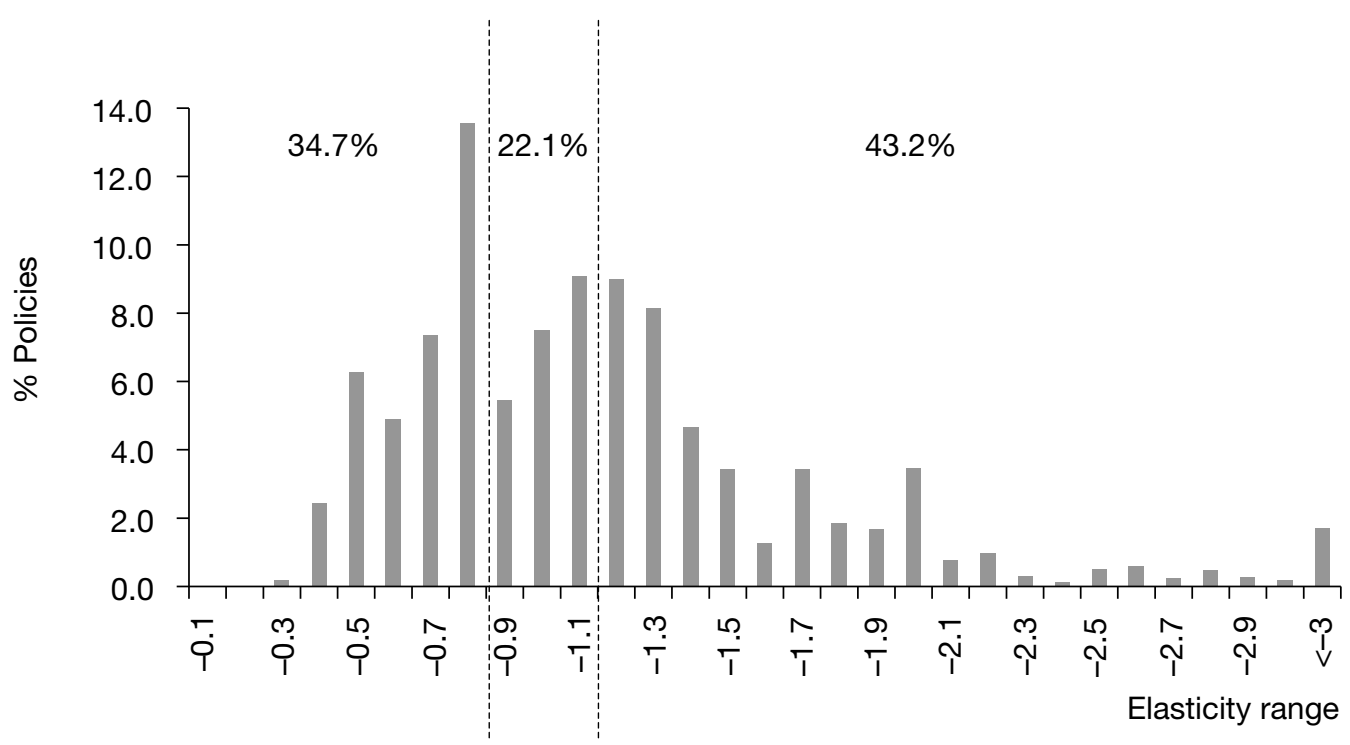

Figure 1 Frequency distribution of elasticities

example shown in Table 6), recording a revenue difference of 5.1 per cent between the perfectly discriminated situation and the strategy characterised by a homogeneous price increase in each segment.

Obviously, other kinds of simulation are possible. Without considering optimal pricing strategies, fitted elasticities offer directions in which prices can be moved. It should be clear that an incorrect pricing process (raising prices in high elasticity segments and lowering prices in low elasticity) is very expensive to the company in terms of missed revenues.

In a competitive environment such price discrimination would be much more important than most of the marketing and promotional campaigns firms are implementing. The room for price discrimination does exist and if companies do not fill this gap they will lose potential revenues as the empirical evidence shown here explicitly suggests.

\section{SUMMARY AND CONCLUSIONS}

In order to improve pricing efficiency in the automotive insurance market a company database containing the relevant information about consumer behaviour and consumer sociodemographics was examined; then customers were clustered in a very large number of clusters crossing all feasible variables in the data set. After that, a simple framework was built to model customers' behaviour with respect to pricing firm policies. By estimating switching probability as an increasing function of the price charged by the firm; price elasticites were then computed. Finally, the estimated parameters were used to find price elasticity-based policies devoted to maximise expected revenues.

Needless to say, ex post aggregation of segments sorted by price elasticities may help in implementing both upgrading in quality services and targeted communication. This approach does not prevent the possibility of modelling price elasticities as a function of psychological and behavioural determinants in order to modify those variables and, finally, to exploit all the willingness to pay embedded in companies' portfolios.

Much in the spirit of genuine oligopoly analysis, the model should be 
Price-elasticity based customer segmentation in the Italian auto insurance market

Table 5: No discrimination versus perfect discrimination (unconstrained pricing)

\begin{tabular}{lllcc} 
& Discrimination & & & \\
& $\mathbf{2 0 0 0}$ & None (1) & Perfect (2) & (2)-(1) \\
\hline Confirmed policies $^{*}$ & 100.0 & 94.3 & 99.7 & 5.4 \\
Total revenues* & 100.0 & 98.7 & 104.8 & 6.1 \\
Switching rate & - & $17.9 \%$ & $13.2 \%$ & $-4.7 \%$ \\
Price index variation rate & - & $5.2 \%$ & $5.2 \%$ & - \\
\hline
\end{tabular}

*For discretion's sake, 2000 values were normalised to 100 . Simulated values follow.

Table 6: No discrimination versus perfect discrimination (constrained pricing)

\begin{tabular}{llllc}
\hline & Discrimination & & & \\
& $\mathbf{2 0 0 0}$ & None (1) & Perfect (2) & (2)-(1) \\
\hline Confirmed policies $^{*}$ & 100.0 & 97.8 & 102.5 & 4.7 \\
Total revenues & 100.0 & 99.6 & 104.7 & 5.1 \\
Switching rate & - & $13.2 \%$ & $12.0 \%$ & $-1.2 \%$ \\
Price index variation rate & - & $2.0 \%$ & $2.0 \%$ & - \\
\hline
\end{tabular}

*For discretion's sake, 2000 values were normalised to 100 . Simulated values follow.

generalised to take into account the reaction functions of other firms to a price change, mainly by inserting cross-price elasticities in the firm's target function.

Nevertheless, the interaction effects should be negligible. In fact, this work has shown great scope for price discrimination, so confirming the market power existing in the Italian automotive insurance market. In their 'local' monopolies, firms seem not to price efficiently. This means that many profitability objectives could be achieved with a more thoughtful price strategy.

It should also be pointed out that the strong reduction in switching rate is an important result. In perspective, it is more important than the direct revenue issues, if it is true that companies want to improve the average return per user by stretching the brand to cover many new and different services besides automotive damage insurance.

The application of the tool described in the paper, would also have the merit of forcing managers to give up pricing strategies based only on sociodemographic variables. So, the use of price elasticities becomes a strategic option to achieve better economic results, higher levels of retention and more guaranteed success for cross-selling activities.

Finally, it is time to let prices play a more central and effective role in marketing and strategic planning in the insurance industry, as they do in other goods and services industries. In the automotive insurance market changing prices is often required. It should become a strategy. Here a way to fulfil this goal has been suggested.

\section{References}

1 Prometeia (2001) 'Switching behaviour in the compulsory automotive insurance market', Prometeia Special Report, Bologna, Italy.

2 Keaveney, S. M. (1995) 'Customer switching behaviour in service industries: An exploratory study', Journal of Marketing, Vol. 59, pp. 71-82.

3 Bolton, R. N. and Myers, M. B. (2003) 'Price-based global market segmentation for services', Journal of Marketing, Vol. 67, No. 3, pp. 108-128.

4 Autorità Garante della Concorrenza e del Mercato (2003) 'Indagine conoscitiva sul settore assicurazione autoveicoli', Roma.

5 ISVAP (2000) 'L'Assicurazione R.C. auto in Italia: Analisi e proposte', Roma.

6 Prometeia (2001) op. cit.

7 Varian, H. (1989) 'Price discrimination' in Schmalensee, R. and Willig, R. D. (eds) 'The handbook of industrial organization', North-Holland, Amsterdam. 